\title{
Evaluation of Staff Motivation Strategies on the Productivity of Nigerian Banking Industry
}

\author{
${ }^{1}$ Ph.D Pauline E. Onyeukwu, ${ }^{2}$ Nkoyo Edet Ekere \\ ${ }^{1}$ Baze University Abuja, Nigeria \\ 2 Nile University of Nigeria, Abuja, Nigeria
}

\begin{abstract}
The study critically evaluated the inadequacy or the inappropriateness of motivational strategies that have beclouded the banking industry subsector overtime which has led to the erosion of public confidence on banks. The methodological framework adopted for the investigation was descriptive survey design using correlational analysis. A questionnaire was administered to 125 respondents selected from three commercial banks which helps in generating the primary data while the secondary data was gotten from the internet, textbooks, journals, etc. The research instrument $w$ as face-validated, and a reliability test was conducted using Cronbach alpha coefficient (a), and the instrument was found reliable and acceptable for use. The research hypotheses were tested using Pearson Product Moment Correlation ( $r$ ) aided by SPSS version 20.0. The findings of the study revealed that there is a significant relationship between staff motivation strategies, the attraction of skilled labor force, labor turnover, fraud incidences in the banking industry and the organizational productivity. These negative tendencies have implicated the performance of the banking business leading to declining in organizational productivity which over time has eroded public confidence. The study concluded that the design of appropriate motivational strategies that can arrest these negative tendencies in the banking industry, therefore, becomes a matter of urgent attention.
\end{abstract}

Keywords: Evaluation, Motivation, Staff, Productivity and industry

\section{Introduction}

Banking industry in the 70 s through 80 s to the 90 s was linked to the preponderances of evidences that the bank workforce were ranked amongst the most highly motivated labor force in the Nigeria labor history. It was an unquestionable fact that, in the early times of banking development in Nigeria, Bank workers were treated as most respectable citizens in Nigeria. By this classification, one could entrust any business transactions into their hands without fear of any contradictions, or misgivings occasioned by unethical and sharp practices that characterized behaviors of workers in other sectors of the economy. By this position, it was a popularly held view that employees of banks are properly and adequately motivated in cash and in -kind to give their best to the industry and the society at large. Hence, until today, motivation remains the only key factor to drive the wheel of the business of the banking industry to greater performance.

There is no doubt that people who are well-motivated will perform better than those who are not; this will lead to increase in efficiency and productivity (Tella, et al., 2007). This top performance can only be achieved when they are driven by enjoyment for the work itself (Lawler, 2003).

It is, therefore, an undeniable fact that the human resource of every organization remains the most important resource; thus, every effort should be made by organizations to ensure their 


\section{Ph.D Pauline E. Onyeukwu, Nkoyo Edet Ekere \\ Evaluation of Staff Motivation Strategies on the Productivity of Nigerian Banking Industry}

effectiveness since without them the organization cannot function well. By this delineation, motivation, therefore, remains a vital force in driving the concept of performance effectiveness and high productivity compendium.

Organizational performance is a product of both ability and level of motivation. Organizational success depends upon members being motivated to use their full talents and abilities, and are directed to perform well in the right areas (Osabiya, 2015).

Motivation involves a constellation of beliefs, perceptions, values, interests, and actions that are all closely related (Lai 2011). As a result, various approaches to motivate one can focus on cognitive behaviors (such as monitoring and strategy use), non-cognitive aspects (such as perceptions, beliefs, and attitudes), or both. Motivation refers to reasons that underlie behavior that is characterized by willingness and volition. Intrinsic motivation is animated by personal enjoyment, interest, or pleasure, whereas extrinsic motivation is governed by reinforcement contingencies (Lai, 2011).

Over the years, different banks in Nigeria have claimed to have provided favorable motivational strategies for their employees to put in their very best. This claim may be true because every organization has a system of reward designed to motivate its employees.

\subsection{Problem Statement.}

Nigerian banks' motivational strategies are not adequate to attract the best skills and professionals into the system. There are still cases of labor turnover, fraud, demotivation and dissatisfied workforce syndrome. These are as a result of the inappropriateness of motivational strategies that have beclouded the banking industry over time.

\subsection{Aim of the Study.}

The erosion of public confidence and inadequate motivational strategies in many Nigerian banks needs to be examined in order to proffer a solution. Hence the aim of the study is to examine to what extent the staff motivation strategies of Nigerian banks can attract the best brains and enhance organizational productivity. It is also to ascerta in if labor turnover and fraud incidences in banks correlate with motivational strategies.

\section{Literature Review}

Azorjen (2005) studied performance-based reward scheme of Teachers in some secondary schools in Kaduna, Nigeria. He discovered that performance depends very much on a credible supporting performance management fra mework that is fair and consistently applied. The basic gap this research tries to fill is to study whether the reward is pecuniary or non-pecuniary and whether sanctions exist for poor performance; duration of the reward, and in particular, whether the reward is given once only, for a limited duration, or permanently; the reward levels, and in particular, whether there are ascending rewards for increased teacher performance or whether the performance evaluation allows teachers to progress to a new salary scale and the scope of the reward, and in particular, whether all teachers who fulfill the criteria are rewarded, or just a specific quota.

James (2001), carried out a study about Performance-Based Pay for Teachers in Gboko, Nigeria using a survey design, put it that interest in performance-based pay for teachers rose in part, from a basic dissatisfaction with the traditional salary schedule. Many policymakers believed that the traditional salary schedule provided no incentive for teachers to demonstrate subject matter competence, improve teaching, or increase academic performance by students.

Al-Aydi (2000), investigated the effect of incentives on the level of performance in the textile industry in Iraq. He found out that there is a weak relationship between the incentives system 
and the level of performance, and between the wages system and the level of performance. Also, there is a strong correlation between rewards and the level of performance, and between appropriate promotion system and level of performance.

Dixit and Bhati (2012), in their study, discovered that poor monetary incentives packages had been a major factor affecting employees' commitment and standard of performance in India. They, however, conclude that for any organization to achieve its objectives in any competitive society, employers of labor must have a thorough understanding of what drives the employees to perform efficiently. Paying employees for performance has been the cornerstone of industrial and business development for centuries. A financial reward has always been important in managing employee's performance, and thus, motivate employees (Armstrong and Taylor, 2010).

Alwabel (2005) investigates the role of financial and moral incentives in raising the performance level of employees from the viewpoint of public security officers participating in the Hajj season. The results showed that there are no incentives standards provided to the officers but the degree of their satisfaction is very high and incentives play a major role in raising the level of performance.

Abang, May-Chiun, and Maw (2009) found that firm performance has important implications for employees and organizations by examining human resource practices and the impact of incentives on manufacturing companies in the Malaysia context. The results have indicated that the two components of human resource practices namely, training and information technology have a direct impact on organizational performance. It was found that incentive is positively related to organizational performance but did not moderate the relationship between both HR practices and organizational performance.

Christen (2006) in his study found that there is a significant difference in people's perception of their being paid on performance versus their desire for such payment system. This exemplifies the disparity between what people feel they deserve for their efforts versus what they receive regarding payment. Interestingly, one of his six hypotheses also reviewed that people of different education levels differ in their preferences for performance and payment.

Chiang et al. (2005) found that the efforts of economists to emphasize the importance of incentives as determinants of organizational performance, while successful to some degree, may have left the mistaken impression that "getting the incentives right" is the only task requiring the attention of senior executives when designing corporate organizations (cited in Chukwuebuka, 2010). The author identifies the incentive-intensive companies envisioned by economists as "mercenary organizations", or companies whose distinguishing feature is nearcomplete reliance on financial rewards and controls. Citing the difficulties of devising an effective incentive system that cannot be gamed (which he calls the organizational equivalent of "an antigravity machine"), the article questions whether such organizations are likely to yield superior performance.

Babaita (2011) triedresearch was to investigate the place of motivation on employees' performance in the Nigerian Banking Industry. The results of the study proved that motivation has a positive impact on employee performance in the banking industry. He recommended maintaining the enthusiasm of employees, for which management must understand the three sets of goals that the great majority of workers seek from their work, and then satisfy those goals. These goals are equity, achievement, and camaraderie. Specifically, the banks in Nigeria need to go back and re-examine their motivation packages. Most of the items the banks see as motivation were not seen as being so by the banks' employees.

The current study is unique in the sense that it looked into the inappropriateness of motivational strategies in Nigerian banking industry instead of the usual motivational strategies studied by 
Ph.D Pauline E. Onyeukwu, Nkoyo Edet Ekere

Evaluation of Staff Motivation Strategies on the Productivity of Nigerian Banking Industry

previous researchers. Therefore, the innovation of the study in Nigerian banking industry cannot be overstated.

\section{Methodology}

The study adopted the correlational design. This accounts for the fact that the study intends to observe the relationships between the variables of the study without any attempt to manipulate or control them. The justification for the use of correlation analysis is based on the fact that the study is interested in knowing if significant relationships exist between the independent and dependent variables, and whether such relationships could be due to 'cause' and 'effect' - in which case, the movement of one variable determines the outcome of the other.

\subsection{Considerations}

182 staff members were drawn within the three banks selected. The sample size of 125 was obtained from the population using Taro Yamane formula.

\section{Data Analysis and Interpretation}

Table 1: Correlation Table Analysis on Dimensions of the Study

\begin{tabular}{|c|c|c|c|c|c|}
\hline & $\begin{array}{l}\text { Organization } \\
\text { Productivity }\end{array}$ & \begin{tabular}{|c|} 
Respondents \\
Perception \\
of Adequacy \\
of Motivation \\
Strategies \\
\end{tabular} & $\begin{array}{l}\text { Respondents } \\
\text { Perception } \\
\text { of Attracting } \\
\text { Best skills }\end{array}$ & $\begin{array}{l}\text { Respondents } \\
\text { Perception of } \\
\text { Labor turnover } \\
\text { correlation with } \\
\text { Motivation }\end{array}$ & \begin{tabular}{|c|} 
Respondents \\
Perception of \\
Fraud incidence \\
and Motivation
\end{tabular} \\
\hline Pearson Correlation & 1 & $.610^{\prime \prime}$ & $.659 "$ & $.947 "$ & $.857^{\prime \prime}$ \\
\hline $\begin{array}{l}\text { Organizational } \\
\text { Productivity } \\
\text { (2-tailed) }\end{array}$ & & .000 & .000 & .000 & 000 \\
\hline 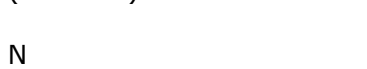 & 120 & 120 & 120 & 120 & 120 \\
\hline Pearson Correlation & $.610 "$ & 1 & $.684 "$ & $.638 "$ & $.674^{\prime \prime}$ \\
\hline $\begin{array}{l}\text { Respondents Perception } \\
\text { of Adequacy of Motivation } \\
\text { Sig. ( } 2 \text {-tailed) }\end{array}$ & .000 & . & .000 & .000 & 000 \\
\hline & 120 & & 120 & 120 & \\
\hline $\begin{array}{l}\text { Pearson Correlation } \\
\text { Respondents Perception } \\
\text { of Attracting Best skills }\end{array}$ & 659" & .684" & 1 & $.715^{\prime \prime}$ & $.788^{\prime \prime}$ \\
\hline Sig. (2-tailed) & $\begin{array}{l}.000 \\
120\end{array}$ & $\begin{array}{l}.000 \\
120\end{array}$ & 120 & $\begin{array}{l}.000 \\
120\end{array}$ & $\begin{array}{l}.000 \\
120\end{array}$ \\
\hline $\begin{array}{l}\text { Pearson Correlation } \\
\text { Respondents Perception } \\
\text { of labor turn over } \\
\text { correlation with motivation } \\
\text { strategies }\end{array}$ & 947 & $.638 "$ & $.715^{\prime \prime}$ & 1 & .815 \\
\hline $\begin{array}{l}\text { Sig. (2-tailed) } \\
\mathrm{N}\end{array}$ & $\begin{array}{l}000 \\
120 \\
.857\end{array}$ & $\begin{array}{l}.000 \\
120 \\
.623^{\prime \prime}\end{array}$ & $\begin{array}{l}.000 \\
120 \\
.788^{\prime \prime}\end{array}$ & $\begin{array}{l}120 \\
.638^{\prime \prime}\end{array}$ & $\begin{array}{l}.000 \\
120 \\
1\end{array}$ \\
\hline $\begin{array}{l}\quad \text { Pearson } \\
\text { Correlation } \\
\text { Respondents Perception of } \\
\text { Fraud incidence and } \\
\text { Motivation } \\
\text { tailed) Sig. (2- }\end{array}$ & .000 & .000 & .000 & .000 & .000 \\
\hline $\mathrm{N}$ & 120 & 120 & 120 & 120 & 120 \\
\hline
\end{tabular}

Source: Field survey, 2017. SPSS v.20 
This chapter presents the data and carries out critical analysis of the data obtained from the respondents after the field work. The study primary data collected through the questionnaire administration as well as secondary data obtained from the companies' financial and other operational records. The chapter presented the data in the table above.

Hypotheses One:

$\mathrm{H} 0: 1$. There is no significant relationship between the adequacy of staff motivation strategies of banks and organizational productivity.

The analysis above shows the $\mathrm{R}$-value is positive $(.610 * *, \mathrm{p}=0.000)$. Since the $\mathrm{p}$-value is less than $0.05(p=0.000<0.05)$, the null hypothesis is rejected, and the alternative which states that there is a significant relationship between the adequacy of staff motivation strategies of banks whereby organizational productivity is accepted.

\section{Hypotheses Two:}

H0:2. The staff motivation strategies of banks have not attracted the best skills that could enhance organizational productivity. For hypothesis two, the staff motivation strategies of banks being able to attract the best skills that could enhance organizational productivity is expressed in the R-value of the table 1 above $(.659 " ", p=0.000)$. Since the $p$-value is less than $0.05(p=$ $0.000<0.05$ ), the null hypothesis is rejected, and the alternative is accepted. This means that the staff motivation strategies of banks are capable of attracting the best skills of human resources that could enhance organizational productivity.

Hypotheses Three:

$\mathrm{HO}: 3$. There is no significant relationship between labor-turnover in banks and their motivational strategies; For hypothesis three, the correlation Table 1 analysis above shows the R-value is positive $(.947 * *, p=0.000)$. This analysis fails to support the acceptance of the null hypothesis because the $p$-value is $0.00(p=0.000<0.05)$. This implies that there is a significant relationship between labor-turnover in banks and their motivational strategies.

There is no significant relationship between fraud incidences in banks and inappropriate motivational strategies. For hypothesis four, which states there is no significant relationship between fraud incidences in banks and inappropriate motivational strategies, it is expressed in the R-value of Table 1 above as $.857 " ", p=0.000$. Since $(p=0.000<0.05$, the null hypothesis is rejected, and the alternative is accepted, this means that there is a significant relationship between fraud incidences in banks and inappropriate staff motivational strategies.

\section{Interpretation}

The Objective One of our study was to determine if the staff motivation strategies of banks are adequate to enhance organizational productivity.

From our statistical Null hypothesis (H0:1.), which proposes that there is no significant relationship between the adequacy of staff motivation strategies of banks and organizational productivity, the findings from the Pearson Product Moment Correlation.

Table 1 , the analysis above shows a positive $\mathrm{R}$-value $(.610 * * \mathrm{p}=0.000)$ indicating a significant positive moderate relationship between staff motivation strategies of the three banks and their adequacy to enhance organizational productivity. The relationship is moderately high given the $r$ value $(0.610$ or $61,0 \%)$ close to 1 which is a perfect positive correlation. The coefficient of determination of shared variance between the two variables is $37.21 \%$ which means that staff motivation helps to explain nearly $74.82 \%$ of the banks' productivity. Given the p-value is less than 0.005 ; it can be reported as statistically significant and small enough to justify rejection of the null hypothesis. This confirms that there is a significant relationship between the adequacy of staff motivation strategies of banks and organizational productivity. 
Objective Two: This was set to determine if staff motivation strategies of banks have attracted the best human resource skills to enhance organizational productivity. Also, the statistical Null Hypotheses Two $(\mathrm{HO} .2)$ proposes that the staff motivation strategies of banks have not attracted the best skills that could enhance the overall organizational productivity. However, the relationship between the findings from the Pearson Product Moment Correlation Table 1, the analysis above expresses the $\mathrm{R}$-value in the table above $(.659 * *, \mathrm{p}=0.000)$ indicating a significant positive moderate relationship between the staff motivation strategies of banks have attracted the best skills that could enhance the overall organizational productivity. The relationship is moderately high given the $r$ value $(0.659$ or $65.9 \%)$ which is close to 1 indicating positive correlation. The coefficient of determination of shared variance between the two variables is $43.43 \%$, which means that the attraction of the best skills through the banks' motivational strategies helps to explain nearly $43.43 \%$ of workers contributions to productivity in the banks. Given the p-value less than 0.05 , it can be reported as statistically significant and small enough to justify rejection of the null hypothesis. This confirms that there is a significant relationship between staff motivation strategies of banks which have attracted best skills into the system and enhanced the overall banks' productivity. This result also led to the fulfillment of the overall research objective postulated earlier in our chapter one of the study.

Objective Three: This objective was "to ascertain if labor-turnover in banks correlate with motivational strategies leading to banks' productivity." Whereas, the hypothesized statistical null hypothesis ( $\mathrm{H} 0: 3$ ) states that, "there is no significant relationship between labor-tumover in banks and their motivational strategies that could lead to banks' productivity."

Aided by the SPSS, the correlation table 1 analysis above shows the R-value is positive $\left(.947^{* *}\right.$, $\mathrm{p}=0.000$ ) indicating a highly significant positive relationship between labor-turn-over in banks and their motivational strategies that could lead to negative impact on the banks' productivity." The relationship is very high given the r value $(0.947$ or $94.7 \%)$ close to 1 which is an ideal positive correlation. The coefficient of determination of shared variance between the two variables is $89.68 \%$ which means that bonuses help to explain nearly $89.68 \%$ of labor-tumover in banks. Given the p-value less than 0,005 , it can be reported as statistically significant and small enough to justify rejection of the null hypothesis. This suggests that the issue of labor turnover is one of the most important issues affecting the efficiency of the employees' performance and the overall productivity of Nigerian banks. This could be attributed to low financial incentives such as allowances and bonuses which were ranked first in importance to raise the efficiency of the performance of employees and could be followed by moral incentives as management complementary effort to help in sustaining productivity levels of the Banks. Objective Four: This was set "to determine if fraud incidences in banks correlate with inappropriate motivational strategies." The attendant statistical null hypothesis (H0:4) proposes that there is no significant relationship between fraud incidences in banks and inapprop riate motivational strategies.

For hypothesis four, which states no significant relationship between fraud incidences in banks and inappropriate motivational strategies, is expressed in the R-value of the table above (.857"', $p=0.000)$. Since the $p$-value is $(p=0.000<0.05)$, the null hypothesis is rejected, and the alternative is accepted. This means that there is a significant relationship between fraud incidences in banks and inappropriate staff motivational strategies.

Aided by the SPSS, the correlation table 25 analysis above shows the R-value is positive $(.857 * *, p=0.000)$ indicating a highly significant positive relationship between fraud incidences in banks and the situations of inappropriate motivational strategies that could have led to a negative impact on banks' productivity over time. 
The relationship is very high given the rvalue $(0.857$ or $85.7 \%)$ close to 1 indicating a positive correlation. The coefficient of determination of shared variance between the two variables is $89.68 \%$ which means that inappropriate motivational strateg ies help to explain nearly $89.68 \%$ of fraud incidences in banks. Given the $p$-value less than 0,005 , it can be reported as statistically significant and small enough to justify rejection of the null hypothesis. This suggests that the issue of fraud incidences are one of the most sensitive and very critical issues affecting the efficiency of the employees' performance and the overall productivity of Nigerian banks. This could also be attributable to low financial incentives such as allowances, bonus, etc. occa sioned by bad policy thrust of the banks.

\section{Findings of the Study}

From the investigation carried out in this research and the relevant hypotheses tested, the study came out with the following findings.

- There is a significant positive moderate relationship between staff motivation strategies of the three banks and their adequacy to enhance organizational productivity. This implication shows that when the motivational strategies put in place by banks are adequate, they must be seen to provide a comfortable platform for all categories of staff in terms of their ability to keep the staff on the job and to as well provide a horizon for further career development and advancement.

- The study equally discovered that there is a significant positive moderate relationship between the staff motivation strategies of banks which can attract the best human resource skills into the system that could enhance the overall organizational productivity. The relationship is moderately high given the $r$ value $(0.659$ or $65.9 \%)$ close to 1 which is a perfect positive correlation. However, this position justifies the reason that most banks may seem to have engaged the services of the professional and skilled workforce but such skilled employees are seen not to be committed to the organizations for reasonable length of time due to inappropriate applications of the career enhancement and development policies. This is accounted for why there are several cases of labor turnover within the banking industry in the recent past.

- Similarly, the study found a highly significant positive relationship between labor turnover in banks and their motivational strategies that could lead to negative impact on the banks' productivity. It was ascertained from the analysis that the implication of inappropriate motivational policy thrusts of banks accounted for the high rate of labor turnover in the Nigerian banks. This has adversely affected the operational viability of the banks, and their inability to manage and retain competently skilled workforce becomes endemic leading to declining in productivity. It was also deduced that since these banks are not able to retain competent workforce over a long period of time, this accounted for inexperience workforce being engaged and who are prone to making unsecured credits available to their customers that would eventually become bad and doubtful debts.

- It was also established from the result that there exists a very strong significant relationship between fraud incidences in banks and inappropriate motivational strategies. This position revealed that the problem of the banks examined is the issue of absence motivational policies in these banks. Rather, the problem of the inappropriateness of such policies did not provide for an adequate job security of the bank workforce, as such dishonest staff amongst them capitalized on any loophole and hit the banks with so many financial misappropriations and other sharp practices.

\section{Conclusions and Recommendations}




\section{Ph.D Pauline E. Onyeukwu, Nkoyo Edet Ekere \\ Evaluation of Staff Motivation Strategies on the Productivity of Nigerian Banking Industry}

Based on the findings of this study, the researchers conclude that, there are highly positive relationships between the dependent variable and the independent variable of the study. This implies that, the staff motivational strategies of banks in Nigeria, their inability to attract, retain and maintain competent workforce, problems of labor turn-over and the incidences of frauds and sharp practices all have strong positive correlation in the overall performance of the banking business leading to decline in organizational productivity. The study also concluded that the design of appropriate motivational strategies that can arrest these negative tendencies in the banking industry, therefore, becomes a matter of urgent attention. This is because the banking industry is the blood stream and life wire of any economic development.

\subsection{Recommendations}

Based on the findings deduced from this study, the following recommendations have been provided for further actions:

- Bank Management should set up motivational programs in conjunction with labor Unions that would cut across all categories of staff. By doing so, inputs of all categories of staff would be sought and whatever the incentive programs that would be put in place will be adequate to both parties regarding quantity and quality.

- The adequacy of such incentives should encompass monetary and non-monetary items and should be built into the annual appraisal forms by clearly defining the terms of such motivations.

- Banks should develop more attractive incentive packages that would unavoidably propel professional and highly skilled staff to pledging their life-long loyalty to the services of the organizations.

- Banks should as a matter of critical need, think out-of-box in benchmarking their motivation and incentive programs with industries such as automobile and oil and gas that usually attract services of a skilled workforce for a long period. For example, companies like General Motors, Toyota Corporation, Mobil Oil Nigeria PIc. are a very good example of companies that sustained and maintained skilled workforce for a longer time.

\section{Acknowledgments}

The authors are grateful to Professor Grace C.O. Nzelibe, Dr. S.I Ukpata, Engr. Edet Ekere, for their support in diverse ways in which they contributed to making this write-up a success. Special thanks to the editors of the journal for the many valuable comments on the previous version of the paper which has improved its quality and content to the present date.

\section{References}

- Al-Aydi, K. (2000). Impact of Incentives on Performance in Public Firms of Cotton Industry

in Iraq: a field Study. Master Thesis, Al al-Bayt University Mafraq.

- Alwabel, A. (2005). The Role of Financial and Moral Incentives on Raising the Performance Level of America: R.R. Donnelley and Sons Company. USA.

- Arab University for Security Sciences (DATE NEEDED). Riyadh, Saudi Arabia. [Online]Available from Arabia. LINK TO THE SOURCE NEEDED

- Armstrong, M. and Taylor, S. (2010) Armstrong's Handbook Of Human Resource Management Practice. 13th ed. London: Kogan Page. Auto-Component Industry. European Journal of Business and Social Sciences, Vol. I (6), pp44-5.

- Azorjen INITIALS NEEDED (2005). Money as a motivator: Some research insights. The experiment examines the effects of intrinsic rewards on intrinsic motivation. Financial incentives and human resource management tools, Human Resource for Health, 4(24).

- Babita INITIALS NEEDED (2011). An Appraisal of Employee Motivation in the Nigerian Banking Industry, 2011 British Journal.ISSN 2048-1268.

- Chiang, F.F.T and Birtch, T. A. (2005). Taxonomy of reward preference: A test of reciprocal causality for absenteeism. Journal of Business Review, Vol. 54 Issue 2, 100-110. 
Ph.D Pauline E. Onyeukwu, Nkoyo Edet Ekere

Evaluation of Staff Motivation Strategies on the Productivity of Nigerian Banking Industry

- Christine, H. Schules (2006). Employees Preferences for Pay System Criteria: A Pay System Survey. A Dissertation presented in Partial Fulfillment of the Requirements for the Degree of Doctor of Philosophy at Capella University, March 2006.

- Chukwuebuka, P. (2010). Information, Accessibility, Utilization and Socio-Economic variables as predicators of quality. Journal of Business Review, Vol. 54 Issue 2, 110-120.

- Dixit, V. and Bhati, INITIALS NEEDED (2012). A study About Employee Commitment and its Impact on Sustained Productivity in India. Indian Journal of Management Sciences.Vol.6 (4).

- Lai, E. R. (2011). Motivation: A literature Review. Pearson Research Report:http:www.Pearsonassessments.com/research

- Lawler, E.E. (2003). Reward Practices and Performance Management System Effectiveness. Organizational Dynamics, 32(4) 396. Crossref

- Mark, H. (2011), Not Just a Living: A Complete Guide to Creating a Business that Gives you Life, Family and Naif Examining country differences" Journal of International Management (11).

- Mueller INITIALS NEEDED (2011). Corporate Governance, Product Market competition and Equity Prices.

- Nelson, B. (2003), Money is not the Root of all Motivation; HealthCare Registration 12(10) July pp 7-9.

- Osabiyi, B.J (2015). The Effect of Employees Motivation on Organizational Performance. Journal of Public Administration and Policy Research, Chicago.7 (4), 62-75. Crossref

- Subbullakshim,S andBurckner May Chium and Maw (2017). A study on self-concept of student studying in colleges in Kanchipuram District-An Empirical Study The journal of Management, Vol. 17,March 2017,ISSN 2278-8247

- Tella,Adeyinka;Ayeni,C.O andPopoola,S.O.(2007). Work motivation, job satisfaction and organizational commitment of library personnel in Academic and Research libraries in Oyo State in Nigeria.Vol.9 (2).Web http/www.uidaho.edu/mbolin/tella2.pdf.12 Nov.2012 